\title{
ASPECTOS CONSERVADORES EN LOS MODELOS LATINOAMERICANOS DEL CAMBIO RADICAL. UN ENSAYO INTERPRETATIVO SOBRE EL ARRAIGO DEL POPULISMO
}

\author{
H. C. F. Mansilla \\ Academia Nacional de Ciencias de Bolivia, Academia Boliviana de la Lengua \\ http://dx.doi.org/10.5209/rev_NOMA.2013.v37.n1.42564
}

\begin{abstract}
Resumen.- Regímenes populistas actuales (como los de Bolivia, Ecuador, Nicaragua y Venezuela) propagan una ideología del cambio radical, pero en muchos aspectos reproducen elementos autoritarios y premodernos de las antiguas civilizaciones indígenas y de la era colonial española. El resultado es la repetición de viejas convenciones: la consolidación de la cultura política del autoritarismo, la formación de élites muy privilegiadas que pasan a constituir las nuevas clases altas y la desinstitucionalización de la vida público-política.
\end{abstract}

Palabras clave.- América Latina, autoritarismo, conservador, modernización, populismo, reconocimiento

Conservative Features in Latin American Models of Radical Change. An Interpretative Essay on the Roots of Populism

\begin{abstract}
Actual populist regimes (like those in Bolivia, Ecuador, Nicaragua, and Venezuela) disseminate an ideology of radical change, but in many aspects they reproduce authoritarian and premodern elements of the ancient indigenous civilizations and of the Spanish colonial time. The result is the repetition of old conventions: the consolidation of the political culture of authoritarianism, the formation of very privileged elites (which build now the upper classes), and the desinstitutionalization of public and political life.
\end{abstract}

Keywords.- authoritarianism, conservative, Latin America, modernization, populism, recognition

\section{La simultaneidad de modernización y autoritarismo}

Para orientarnos adecuadamente en un mundo cada vez más complejo e imprevisible debemos ensayar en las ciencias sociales una estrategia que combine una compilación fidedigna de datos empíricos e históricos con juicios críticos valorativos, y estos últimos deberían estar fundamentados de manera razonable y plausible. También para una función esencial del quehacer intelectual, la praxis política, necesitamos generar interpretaciones que se sobrepongan a la coyuntura del momento y a las modas de la temporada, y para ello es preciso un esfuerzo 
exegético inspirado por un impulso humanista, por más devaluada que parezca estar hoy la inclinación clásica a aprender de los antecedentes histórico-sociales.

Estos factores pueden ayudarnos a comprender el vigoroso arraigo que siguen exhibiendo procesos como el peronismo en Argentina, los regímenes populistas en Bolivia, Ecuador, Nicaragua y Venezuela, las diversas variantes de la doctrina socialista, las concepciones nacionalistas y el indigenismo / indianismo ${ }^{1}$ en regiones con fuerte presencia de población aborigen. Atribuir cualidades comunes a todos estos fenómenos es ciertamente un acto arriesgado, pero la tesis central de este ensayo asevera que la praxis cotidiana de los regímenes del cambio radical en América Latina y, en menor medida, sus productos ideológicos, contienen elementos sustanciales de las tradiciones premodernas de esta área geográfico-cultural, elementos que aseguran su popularidad, por un lado, y que dificultan una autoconsciencia crítica de los involucrados, por otra. Este último factor tiende a consolidar una amplia vigencia de los aspectos conservadores provenientes la fusión de las tradiciones indígenas precolombinas con la herencia hispano-católica.

Conservador significa en este contexto rutinario y convencional. Todos los pueblos han mantenido rutinas y convenciones durante largo tiempo sin ponerlas en cuestionamiento y sin someterlas a una crítica racional. Ahí reside su fuerza: tienen vigencia a partir de ellas mismas. Son normas de orientación obvias, sobreentendidas, respetadas por una buena parte de la población, consideradas como algo entrañable e inconfundible. Llegan a ser apreciadas como rasgos distintivos de lo auténticamente propio, es decir en cuanto signos de la identidad colectiva $^{2}$. A largo plazo, sin embargo, la preservación de rutinas y convenciones devenidas obsoletas y hasta irracionales constituye un obstáculo notable para todo proceso genuino de evolución y contribuye a alargar la vida de hábitos sociales inhumanos y engorrosos.

A estas normas de la tradición conservadora latinoamericana pertenecen los códigos informales o paralelos ${ }^{3}$, de naturaleza oral, contrapuestos a los códigos formales, transmitidos como estatutos escritos. A simple vista los primeros tienen un carácter gelatinoso, cambiante e irracional, mientras que los últimos poseen una estructura lógica y pueden ser enseñados e interpretados de manera homogénea, sistemática y

1 Sobre la diferencia entre indigenismo e indianismo cf. Jean-Pierre Lavaud, De l'indigénisme à l'indianisme: le cas de la Bolivie, en: PROBLEMES D'AMERIQUE LATINE (París), № 7, octubre / diciembre de 1992, pp. 63-82; José Alcina Franch, El indianismo de Fray Bartolomé de Las Casas, en: José Alcina Franch (comp.), Indianismo e indigenismo en América, Madrid: Alianza 1990, pp. 34-44.

2 Cf. Alejandro Grimson, Los límites de la cultura. Crítica de las teorías de la identidad, Buenos Aires: Siglo XXI 2011; Nelly Arenas, Globalización e identidad latinoamericana, en: NUEVA SOCIEDAD (Caracas), № 147, enero-febrero de 1997, pp. 121-131; Jorge Larraín Ibáñez, Modernización, razón e identidad en América Latina, Santiago de Chile: Andrés Bello 1996.

3 Cf. los excelentes estudios de Peter Waldmann, Guerra civil, terrorismo y anomia social. El caso colombiano en un contexto globalizado, Bogotá: Norma 2007, especialmente el capítulo 6: "Inseguridad jurídica, pluralismo normativo y anomia social en América Latina", pp. 169-188; y Peter Waldmann, El Estado anómico. Derecho, seguridad pública y vida cotidiana en América Latina, Madrid / Frankfurt: Iberoamericana / Vervuert 2006, pp. 11-25. 
permanente. Los códigos informales no se aprenden mediante libros, cursos y universidades, sino en la práctica de cada día. Esta es su gran ventaja: su validez está por encima o más allá de los ejercicios de la lógica discursiva. Los códigos informales viven en el silencio y la sombra, pero son seguidos por una gran parte de la población con un acatamiento sumiso y hasta con obediencia afectuosa. En este contexto el carácter conservador de una sociedad puede ser detectado por el grado de aprecio que sus habitantes exhiben frente a los códigos informales y por la resistencia generalizada a ponerlos en cuestionamiento, lo que es percibido a menudo como un ataque a la identidad colectiva.

Conservador puede ser interpretado también como favorable a la preservación del medio ambiente y de los ecosistemas naturales. En la realidad cotidiana este sentido conservacionista es prácticamente desconocido en América Latina. La inmensa mayoría de sus habitantes, independientemente de su origen geográfico, social, o étnico, no es conservadora en la acepción ecológica: no cuida de manera conveniente y efectiva los vulnerables suelos y paisajes y más bien se consagra con genuino denuedo a destruir la naturaleza y a dilapidar los recursos naturales.

La simultaneidad de modernización y autoritarismo bajo un manto cultural de conservadurismo puede ser descrita someramente de la siguiente manera. El colapso del socialismo a nivel mundial, los resultados socio-económicos generalmente mediocres de los regímenes populistas y el desprestigio de doctrinas radicales en el ámbito académico no han mellado decisivamente la popularidad de las ideologías del cambio radical y de los caudillos carismáticos que las personifican. Contra este argumento se puede afirmar que la mayoría de las sociedades latinoamericanas han experimentado un fuerte proceso de modernización a partir de la Segunda Guerra Mundial, proceso que en los campos político-institucional y sociocultural habría producido una aceptable democratización y una severa reducción de las tendencias autoritarias $y$, por consiguiente, de las formas arcaicas de interrelacionamiento humano. Pero esta democratización ha sido antiliberal largo tiempo y en muchos países; se ha reducido a una mayor participación de los estratos inferiores de la sociedad respectiva en la vida público-política (o a la ilusión de que esto es así) y ha dejado de lado, por lo menos parcialmente, la construcción del Estado de derecho, el pluralismo ideológico y la vigencia irrestricta de los derechos humanos $^{4}$. En el fondo los rasgos positivos de esta democracia convencional y rutinaria - es decir: de la aceptada generalmente en las regiones con modernización incompleta - estaban y están encarnados en la homogeneidad social y la unanimidad política, y los negativos en la diversidad de intereses, la división de poderes, la competencia abierta de todo tipo y el pluralismo teórico e ideológico ${ }^{5}$. No es, por

4 Cf. los estudios críticos: Carlos de la Torre / Enrique Peruzzotti (comps.), El retorno del pueblo. El populismo y las nuevas democracias en América Latina, Quito: FLACSO 2008; Kurt Weyland / Carlos de la Torre et al., Releer los populismos, Quito: CAAP 2007; Rafael Quinteros, El mito del populismo, Quito: Abya Yala 2005.

5 Glen C. Dealy, The Tradition of Monistic Democracy in Latin America, en: Howard J. Wiarda (comp.), Politics and Social Change in Latin America. The Distinct Tradition, Amherst: Massachusetts U. P. 1982, pp. 77-80; Enrique Krauze, Siglo de caudillos, México: Tusquets 1994. 
supuesto, una cultura cívica moderna. Esto ha cambiado ciertamente a partir de 1980 mediante una poderosa ola de democratización liberal y pluralista, pero desde comienzos del siglo XXI se expande nuevamente una variante de la tradición autoritaria, que dice ser simultáneamente democrática, nacionalista, popular y antielitista ${ }^{6}$ y cuyas raíces se habían mantenido muy robustas en la zona de los Andes, en América Central y México.

Algunos países, como Argentina, Uruguay y Chile, iniciaron su proceso de modernización ya en la segunda mitad del siglo XIX, y es obvio que sus herencias culturales no son idénticas al resto de América Latina, aunque precisamente en estas sociedades se dieron las dictaduras más sangrientas del continente en la segunda mitad del siglo XX. Por ello se puede aseverar que en casi toda América Latina se perciben notables insuficiencias en las esferas concernientes a la política, la vida cotidiana y las creencias sociales, como lo muestra, por ejemplo, la persistencia del peronismo en Argentina.

Por ello y en el marco de este breve ensayo debemos considerar la siguiente hipótesis. Es probable que la pervivencia de ciertas tradiciones culturales, consideradas por las poblaciones respectivas como positivas y, además, como favorables a una fuerte identidad colectiva ${ }^{7}$, impida, dentro de ciertos límites, el advenimiento de un orden plenamente moderno, basado en la racionalidad de los nexos humanos, el Estado de derecho y las prácticas democráticas. Y justamente esta carencia de una modernidad político-cultural debe ser vista como la causa de una mentalidad todavía muy expandida que, en el plano económico, dificulta la creación de una riqueza social más o menos amplia.

Como se sabe, los procesos de modernización han generado una especialización de funciones, una diferenciación de los tejidos sociales y una expansión sin precedentes de los estratos medios. El fenómeno más importante y curioso es, empero, la pervivencia de mentalidades premodernas en medio de la modernización acelerada. Actitudes autoritarias, prerracionales, convencional-conservadoras y tradicionalistas siguen vigentes paralelamente a la adopción de normativas occidentales modernas en la esfera económica y en la administración pública.

\section{La modernización del ámbito indígena y el surgimiento de ideologías}

6 Un testimonio particularmente elocuente de esta corriente en: Gilberto López y Rivas, Mexiko: zwischen "gescheitertem" Staat und einer Demokratie der Autonomien (México: entre el Estado "fallido" y una democracia de las autonomías), en: Leo Gabriel / Herbert Berger (comps.), Lateinamerikas Demokratien im Umbruch (Las democracias latinoamericanas en cambio radical), Viena: Mandelbaum 2010, pp. 70-107.

7 Cf. los tempranos testimonios favorables a esas tradiciones culturales percibidas como fundamentos de una identidad colectiva propia: Guillermo Bonfil Batalla, Identidad y pluralismo cultural en América Latina, San Juan de Puerto Rico: CEHASS 1992; Steve Stern (comp.), Resistance, Rebellion and Consciousness in the Andean Peasant World, Madison: Wisconsin U.P. 1987; Xavier Albó, La cara campesina e india de nuestra historia, La Paz: CIPCA 1990; Xavier Albó (comp.), Raíces de América. El mundo aymara, Madrid: Alianza / UNESCO 1987. 


\section{revolucionarias que enaltecen el pasado}

La persistencia del autoritarismo parece ser más acusada en los antiguos núcleos del colonialismo español ${ }^{8}$, como el área andina, porciones de América Central y México, que coinciden con las áreas de las grandes civilizaciones precolombinas. Especialmente en estos casos hay que analizar los vínculos entre el legado indígena, la herencia colonial ${ }^{9}$, la religiosidad popular y la mentalidad preservada en amplios sectores sociales, factores que son a menudo la base del apoyo de las tendencias populistas ${ }^{10}$. Como están en juego varios elementos de la llamada corrección política, se trata, manifiestamente, de un tema incómodo. Esta afirmación no menosprecia los notables logros de los imperios incaico y azteca (y de las culturas que los antecedieron) en muchos terrenos de la actividad humana, logros que se extienden desde la arquitectura y la infraestructura hasta prácticas de solidaridad inmediata y un sentimiento estable de seguridad, certidumbre e identidad, lo cual no es poco en cualquier contexto histórico. Pero: las civilizaciones precolombinas no conocieron ningún sistema para diluir el centralismo político, para atenuar gobiernos despóticos o para representar en forma permanente e institucionalizada los intereses de los diversos grupos sociales y de las minorías étnicas. La homogeneidad era su principio rector, como puede constatarse parcialmente aun hoy en el seno de las comunidades campesino-indígenas que han permanecido más o menos al margen del proceso de modernización. Esta constelación histórico-cultural no fomentó el surgimiento de pautas normativas de comportamiento social y de instituciones gubernamentales que resultasen a la larga favorables al individuo como persona autónoma, a los derechos humanos como los concebimos hoy, a una pluralidad de intereses y opiniones que compitiesen entre sí y, por consiguiente, al florecimiento de un espíritu críticocientífico.

A comienzos del siglo XXI casi todas las comunidades indígenas del Nuevo Mundo se hallan inmersas en complejos procesos de modernización. Estos últimos han sido inducidos por factores exógenos, como la expansión de la frontera agraria, el contacto diario con el mundo globalizado y la influencia de la escuela y de los medios masivos de comunicación. En la actualidad las etnias indígenas en toda América Latina viven mayoritariamente en el ámbito urbano, trabajan según las normas de la producción capitalista (o están bajo el ascendiente de las mismas en el seno de la economía informal) y se hallan bajo la influencia de los valores de orientación occidental en los campos del consumo y la diversión. Esta constelación es

8 Cf. las obras que no han perdido vigencia: Claudio Véliz, The Centralist Tradition of Latin America, Princeton: Princeton U. P. 1980; Horst Pietschmann, Estado colonial y mentalidad colonial: el ejercicio del poder frente a distintos sistemas de valores en el siglo XVIII, en: Antonio Annino et al., America Latina: dallo stato coloniale allo stato nazionale, Turín: Angeli 1985, vol. II, pp. 434-449.

9 Magali Sarfatti, Spanish Bureaucratic Patrimonialism in America, Berkeley: California U. P. 1966; Mario Góngora, Studies in the Colonial History of Spanish America, Cambridge U. P. 1975.

10 Cf. David Scott Palmer, The Politics of Authoritarianism in Spanish America, en: James M. Malloy (comp.), Authoritarianism and Corporatism in Latin America, Pittsburgh: Pittsburgh U. P. 1977, pp. 377412; Jorge Nieto Montesinos (comp.), Sociedades multiculturales y democracias en América Latina, México: UNICEF 1999; Sabine Kurtenbach et al., Die Andenregion - Neuer Krisenbogen in Lateinamerika (La región andina - nuevo centro de crisis en América Latina), Frankfurt: Vervuert 2004. 
particularmente fuerte en las generaciones juveniles. Paralelamente a esto - y aquí se hace patente la ambigüedad de los legados culturales ${ }^{11}$ - las comunidades indígenas del presente conservan a menudo rasgos autoritarios en la estructuración social, en la mentalidad público-política y también en la vida cotidiana y familiar. Estos fenómenos no concitan el interés de los círculos académicos e intelectuales, la mayoría de los cuales fomenta una autovisión de los aborígenes basada en un panorama idealizado y hasta falso del pasado y del presente. No sólo en el campo universitario, sino en lo que podemos llamar la cultura popular se ha conformado una amplia convicción acerca del núcleo identificatorio del propio pasado histórico, que tiene las siguientes características. Se supone que las grandes tradiciones solidarias del pasado están aun vigentes en las comunidades campesinas y en la vida rural; asimismo se cree que las culturas precolombinas habrían sido profundamente democráticas y no habrían conocido relaciones de explotación y subordinación ${ }^{12}$. En el ámbito andino se asevera además que la civilización incaica y también las culturas anteriores deberían ser vistas como un socialismo revolucionario y original, pero en estadio embrionario ${ }^{13}$.

Es precisamente esta concepción la que dificulta la difusión de una mentalidad pluralista y democrática, pues promueve en el fondo una percepción complaciente y embellecida de la propia historia, atribuye todas las carencias del pasado y de la actualidad a los agentes foráneos y evita un cuestionamiento de los valores de orientación de las civilizaciones aborígenes. En este campo las corrientes izquierdistas y nacionalistas no han significado beneficios cognoscitivos y más bien han contribuido a consolidar los aspectos autoritarios del mundo indígena ${ }^{14}$. También hoy entre cientistas sociales existen tabúes, aun después del colapso del socialismo. Así como antes entre marxistas era una blasfemia impronunciable achacar al proletariado algún rasgo negativo, ahora sigue siendo un hecho difícil de aceptar que sean los pueblos indígenas y los estratos sociales explotados a lo largo de siglos - y por esto presuntos depositarios de una ética superior y encargados de hacer avanzar

\footnotetext{
11 Helga von Kügelgen (comp.), Herencias indígenas, tradiciones europeas y la mirada europea, Madrid / Frankfurt: Iberoamericana / Vervuert 2002.

12 El testimonio más conocido e ilustre de esta corriente: Guillermo Bonfil Batalla, Aculturación e indigenismo: la respuesta india, en: José Alcina Franch (comp.), op. cit. (nota 1), pp. 189-209, aquí p. 194, 197, 199; Guillermo Bonfil Batalla (comp.), Utopía y revolución. El pensamiento político contemporáneo de los indios en América Latina, México: Nueva Imagen 1981.

13 Cf. entre muchos otros: Félix Cárdenas, Utopía andina. El proyecto comunero andino, Oruro: Serie 500 1990; Silvia Rivera Cusicanqui, Oprimidos pero no vencidos. Luchas del campesinado aymara y quechua de Bolivia 1900-1980, La Paz: HISBOL 1984; Diego Irarrazával, Nueva época en las comunidades, religiones y culturas, en: NUEVA SOCIEDAD, № 136, marzo-abril de 1995, pp. 8295, especialmente p. 92.

14 Franco Gamboa Rocabado resaltó el carácter contestatario del indianismo y su resistencia con respecto al "orden occidental", pero criticó asimismo su índole antidemocrática, que enaltece y edulcora inadecuadamente las formas elementales de la organización social y económica de la época prehispánica.- Franco Gamboa Rocabado, Bolivia y una preocupación constante: el indianismo, sus orígenes y limitaciones en el siglo XXI, en: ARAUCARIA. REVISTA IBEROAMERICANA DE FILOSOFÍA, POLITICA Y HUMANIDADES (Sevilla), vol. 11, № 22, julio-diciembre de 2009, pp. 125151, aquí pp. 126-127.
} 
la historia - los que encarnan algunas cualidades poco propicias con respecto a la cultura cívica moderna, a la vigencia de los derechos humanos y al despliegue de una actitud básicamente crítica ${ }^{15}$.

No hay duda de que casi todos los sectores indígenas intentan adoptar lenta pero seguramente numerosos rasgos básicos del mundo occidental, sobre todo en los campos de la técnica y la economía. Se trata de un proceso complejo y hasta traumático, pues al admitir aspectos relevantes de un modelo civilizatorio extranjero, se da inexorablemente una renuncia paulatina, pero segura, a legados culturales propios que aun han permanecido vivos en la memoria colectiva. En este contexto se puede percibir un designio omnipresente de modernización técnico-económica (según standards occidentales), que sucede paralelamente a una reinvención de la tradición. Esta última se manifiesta como el redescubrimiento interesado y hasta manipulado de los valores ancestrales indígenas. En este campo los que hablan a nombre de los indígenas tienen un dilatado campo de acción. El resultado de este renacimiento más o menos artificial de las concepciones tradicionales aborígenes es la creación de una doctrina generalmente aceptada que trata de mitigar - como históricamente inevitable - esa adopción de normativas foráneas y encubrir las carencias propias de desarrollo (mediante el renacimiento forzado de prácticas culturales vistosas, pero inofensivas).

Algo similar ocurre en la actualidad con los estudios en torno a los movimientos sociales y a la llamada economía solidaria ${ }^{16}$. Estos ejercicios intelectuales tienden a enaltecer la misión "histórica" de los movimientos sociales, a embellecer románticamente sus actividades "antisistémicas" y a equiparar su función central con la de los tradicionales partidos socialistas y comunistas del periodo heroico. Aunque existen valiosas voces críticas, la mayoría de estos escritos presupone que los movimientos sociales construyen un modelo realmente distinto de economía, que sería la realización del viejo sueño humano de igualdad, solidaridad y reciprocidad ${ }^{17}$, lo que tiene que ver mucho más con los anhelos de los autores que con la realidad cotidiana, siempre más prosaica que la esfera de la teoría pura. Algunos de los estudios más pretenciosos acerca de esta temática terminan en una oscura apología de fuerzas políticas de clara factura colectivista y en una celebración vacía de las ideologías concomitantes ${ }^{18}$. La mayoría de los investigadores guarda un silencio

15 Cf. por ejemplo: Angela Meentzen, Indígena und Politik im Andenraum: Peru (Indígenas y política en la zona andina: Perú), en: KAS-AUSLANDSINFORMATIONEN (Berlin), vol. 21, № 1, enero de 2005, pp. 30-56; Stefan Jost, Indigener Protest in Bolivien. Ziele einer radikalisierten IndígenaBewegung (Protesta indígena en Bolivia. Metas de un movimiento indígena radicalizado), en: ibid., pp. 57-78.

16 Martín Tanaka / Francine Jácome (comps.), Desafíos de la gobernabilidad democrática. Reformas político-institucionales y movimientos sociales en la región andina, Lima: IEP 2010.

17 Clarita Müller-Plantenberg, Was heisst: die Wirtschaft demokratisieren? Vom Neoliberalismus zur Solidarwirtschaft (¿Qué significa democratizar la economía? Del neoliberalismus a la economía solidaria), en: Leo Gabriel / Herbert Berger (comps.), op. cit. (nota 6), pp. 300-336, especialmente pp. 302-303.

18 Un ejemplo de ello: Hans-Jürgen Burchardt, The Latin American Paradox: Convergence of Political Participation and Social Exclusion, en: INTERNATIONALE POLITIK UND GESELLSCHAFT 
sintomático en lo referente a la estructuración interna, la cultura política de los adherentes, la formación de élites dirigentes y los intereses corporativos, que, después de todo, conforman los factores de la vida cotidiana de los movimientos sociales y de las organizaciones políticas indígenas ${ }^{19}$.

Lo que finalmente emerge en la vida real de la actualidad latinoamericana es una amalgama contradictoria que tiene una relevancia decisiva para la configuración de la identidad nacional, lo que probablemente tiene vigencia tanto en el mundo indígena como en la totalidad de las sociedades latinoamericanas. En pocas palabras el resultado puede ser descrito como (a) la aceptación de los elementos técnicoeconómicos de la civilización occidental y de las metas normativas de evolución histórica (modernización, urbanización, industrialización) y (b) la simultánea preservación de valores tradicionales propios en los ámbitos de la política, la vida familiar y las manifestaciones artísticas populares.

\section{La problemática del reconocimiento y la dignidad y la posición ambigua frente a la cultura occidental}

Los elementos conservadores de cuño restaurativo ${ }^{20}$ en las ideologías populistas y las doctrinas indigenistas revolucionarias pueden ser comprendidos, por lo menos parcialmente, si analizamos el énfasis recurrente en cuestiones emotivas como la dignidad colectiva mellada secularmente y la necesidad de reconocimiento por los otros. Las teorías contemporáneas sobre el reconocimiento ${ }^{21}$ han tematizado este aspecto fundamental que se da, entre muchos otros casos, cuando se produce un choque traumático y asimétrico entre civilizaciones diferentes. Uno de los ejemplos más notables ha sido la colisión entre las culturas precolombinas del Nuevo Mundo y la conquista española. Y, por supuesto, lo relevante para hoy es la forma cómo los intelectuales latinoamericanos mantienen vivo ese dolor colectivo mediante explicaciones unilaterales que cargan las responsabilidades históricas sobre los

(Berlin), vol. 2010, № 3, pp. 40-51, especialmente p. 46.

19 René Kuppe, Das Ringen ums Recht: vom liberalen zum plurinationalen Konstitutionalismus (La pugna por el derecho: del constitucionalismo liberal al plurinacional), en: Leo Gabriel / Herbert Berger (comps.), op. cit. (nota 6), pp. 111-144, especialmente pp. 113-114; Christian Cwik, Venezuela: partizipative und direkte Demokratie. Über das venezolanische Demokratieverständnis im 21. Jahrhundert (Venezuela: democracia participativa y directa. Sobre la concepción venezolana de democracia en el siglo XXI), en: ibid., pp. 225-251, aquí p. 238.

20 Numerosas doctrinas y prácticas revolucionarias han intentado, en el fondo, la restauración del orden social anterior a los procesos modernizadores. El concepto de revolución tiene el sentido de dinamismo histórico radical, pero también el de un retorno a una edad considerada como paradigmática. En la magna obra de Karl Marx el término posee ambas acepciones. Cf. estudio exhaustivo de Karl Griewank, Der neuzeitliche Revolutionsbegriff. Entstehung und Geschichte (El concepto contemporáneo de revolución. Origen e historia), Frankfurt: Suhrkamp 1973.

21 Axel Honneth, Kampf um Anerkennung. Zur moralischen Grammatik sozialer Konflikte (La lucha por el reconocimiento. Sobre la gramática moral de los conflictos sociales), Frankfurt: Suhrkamp 1992; Axel Honneth, Das Ich im Wir. Studien zur Anerkennungstheorie (El yo en el nosotros. Estudios sobre la teoría del reconocimiento), Frankfurt: Suhrkamp 2010; Charles Taylor, El multiculturalismo y la "política del reconocimiento", Madrid: FCE 2003. 
conquistadores, sus descendientes, sus valores culturales y sus instituciones. No hay duda de que se produjo una especie de "vulneración narcisista"22 en el seno de las civilizaciones precolombinas, que perdura parcialmente hasta hoy. Esta herida clama por compensaciones de variado tipo y ha engendrado, al mismo tiempo, atribuciones unilaterales de culpa y teorías conspirativas que configuran una parte de la mentalidad colectiva, sobre todo de sus elementos emotivos. Los miembros de estas sociedades vulneradas culturalmente reaccionan con extrema irritabilidad con respecto a ofensas reales o imaginarias, irritabilidad que puede ser instrumentalizada y manipulada fácilmente para los fines más diversos. De esta manera se extiende el discreto manto del silencio y el olvido sobre las características propias de las culturas autóctonas que han contribuido también a los fenómenos negativos que ahora se resumen bajo el rótulo de subdesarrollo.

Es indudable que la expansión de la civilización occidental en México, América Central y la zona andina ha conllevado un sentimiento colectivo amplio e intenso de vulneración de la cultura ancestral. Es como una herida cultural profunda, que no ha podido ser curada del todo en el curso de los siglos. Este rasgo nos lleva sobre la pista más importante de esta problemática. Los teóricos de la revolución radical y sobre todo aquellos que han articulado los agravios de las sociedades indígenas aseveran una y otra vez que la civilización moderna, basada en la ciencia y la tecnología, en el racionalismo occidental y en el individualismo egoísta, no ha podido ser aceptada - o sólo parcialmente - por las comunidades aborígenes del Nuevo Mundo. Estas últimas sienten que su ética colectivista y solidaria, que ahora experimenta un renacimiento artificial, no es congruente con los principios derivados de la mentalidad europea. Pero no es únicamente un problema de ethos social, sino una sensibilidad generalizada en torno a los efectos prácticos irradiados por la civilización occidental.

Aquí es imprescindible señalar que las comunidades indígenas de la actualidad no se preocupan, en general, por problemas como identidad colectiva o fidelidad a sus tradiciones, sino que actúan pragmáticamente, usando lo que les conviene de otros legados civilizatorios según las necesidades del momento. Pero por debajo de esta actitud pragmática hay una vivencia difusa y muy extendida de incomodidad y extrañamiento, vivencia que es articulada y exacerbada por los representantes intelectuales y políticos de las comunidades indígenas. Estas últimas tienen una relación ambivalente con la modernidad occidental: admiran y usan sus productos técnicos, sus avances en los campos de la medicina, los transportes y las comunicaciones, pero no atribuyen la relevancia adecuada al ámbito del pensamiento crítico y el debate libre que posibilitó la actual evolución científica, que es, a su vez, el fundamento del progreso tecnológico. Los que hablan en nombre de las comunidades indígenas no pueden explicar y menos aceptar estas raíces del éxito de la civilización occidental, y entonces reducen su filosofía de la historia a concebir la vinculación entre el Nuevo Mundo y Europa como si hubiera sido sólo una serie

22 Hans Magnus Enzensberger, Schreckens Männer. Versuch über den radikalen Verlierer (Hombres del miedo. Ensayo sobre el perdedor radical), Frankfurt: Suhrkamp 2006, p. 41. 
interminable de conquistas militares, explotación económica y degradación moral de parte de la civilización europea. Además se supone que el Occidente, simultáneamente odiado y envidiado, habría quebrado la "unidad espiritual" ${ }^{23}$ de las sociedades premodernas no occidentales, trayendo una civilización militar y técnicamente exitosa, pero moralmente superficial, que tendría los rasgos de un materialismo vulgar y de una democracia de mercaderes.

Las comunidades indígenas y, en realidad, una gran parte de las sociedades latinoamericanas viven en una ambigüedad fundamental. Utilizan todos los días los inventos y procedimientos de la cultura moderna, sin comprender de manera adecuada las bases de esa misma cultura. Una constelación de tal tipo, que se manifiesta como liminarmente ambigua es, como se sabe, el punto de partida para sentirse mal consigo mismo, y este malestar tiñe parcialmente la existencia de una buena porción de las naciones latinoamericanas. No afecta, como se dijo, la esfera de la vida económica, pero sí el ámbito de la política y la formación de identidades colectivas.

Este contexto genera la necesidad de un mecanismo de compensación. Entre los efectos del mismo está el impulso de restaurar la propia dignidad, considerada como vulnerada por la historia de los últimos siglos. No hay duda de que el llamado "colonialismo interno" ${ }^{24}$ ha generado un descenso de la auto-estima en muchas áreas culturales y geográficas de América Latina. Este ha producido, a su vez, un anhelo de indemnización, la "sed de alivio de las duras cargas derivadas de su lugar social secundario, despreciado" ${ }^{25}$ que muchos latinoamericanos creen percibir en el horizonte globalizado del presente.

Uno de los factores del éxito de los líderes populistas de la actualidad consiste en que la opinión pública cree que ellos pueden y deben vengar los agravios históricos y reparar las injusticias sufridas. El ordenamiento socio-político de las últimas décadas en América Latina no satisface plenamente las necesidades de reconocimiento que se derivan de la vulneración de la propia integridad, el honor y la dignidad (y menos aun el periodo neoliberal a partir aproximadamente de 1980). La injusticia social, como afirma Axel Honneth, es percibida en primer término como humillación y desprecio, es decir como un problema existencial y moral, y recién en segundo lugar como un asunto económico (concerniente, por ejemplo a una redistribución de

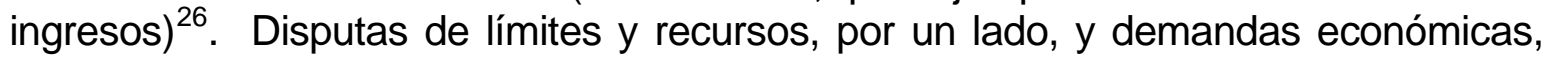
por otro, son el fondo transables y negociables, pero los agravios morales e históricos

23 Ian Buruma / Avishai Margalit, Okzidentalismus. Der Westen in den Augen seiner Feinde (Occidentalismo. El Oeste en los ojos de sus enemigos), Munich: Hanser 2004, pp. 10-13, 60-61.

24 La concepción proviene de Pablo González Casanova, Sociología de la explotación, México: Siglo XXI 1969, pp. 221-250, 260-263.

25 Gonzalo Mendieta Romero, Extractos de un informe apócrifo de una burócrata internacional, en: PÁGINA SIETE (La Paz) del 24 de marzo de 2012, p. 17.

26 Axel Honneth, Umverteilung als Anerkennung. Eine Erwiderung auf Nancy Fraser (Distribución como reconocimiento. Una réplica a Nancy Fraser), en: Nancy Fraser / Axel Honneth, Umverteilung oder Anerkennung? Eine politisch-philosophische Kontroverse (¿Distribución o reconocimiento? Una controversia político-filosófica), Frankfurt: Suhrkamp 2003, pp. 129-224, aquí pp. 155-156. 
encuentran difícilmente una solución que satisfaga a todos los involucrados. Se trata de fenómenos que sólo arduamente pueden ser traducidos a un lenguaje racional y comprensible para otros grupos humanos; la reparación "justa" se encuentra en el plano simbólico y ético, y sólo a largo plazo.

El ansia por dignidad y reconocimiento y las dificultades de su satisfacción aparecen claramente en un interesante ensayo de Adolfo Gilly ${ }^{27}$. En un texto que combina un estilo dramático-emotivo con un marxismo modernizado por la obra de Antonio Gramsci, el postmodernismo y los estudios culturales contemporáneos, Gilly logra capturar el sentimiento generalizado de la población indígena de los Andes que no ha sido modernizada. Aquí aflora la creencia - ahora ampliamente difundida mediante la labor de los intelectuales indianistas e indigenistas - acerca de esencias colectivas, inmutables al paso del tiempo, que no son explicitadas racionalmente, sino evocadas con mucho sentimiento, como si ello bastara para intuirlas adecuadamente y fijarlas en la memoria colectiva de la población andina. Estas esencias se manifiestan en los elementos de sociabilidad, folklore y misticismo (la música, la comida, la estructura familiar, los vínculos con el paisaje, los mitos acerca de los nexos entre el Hombre y el universo), que conforman, según Gilly y una infinidad de autores actuales, el núcleo de la identidad colectiva andina y de su dignidad ontológica superior. Se trata de una evocación que hace renacer un tiempo y un mundo, y para ello hay que tener una empatía a priori con ese universo, que no puede ser comprendido mediante un análisis a posteriori. Para entenderlo hay que tomar partido por él, por sus habitantes, sus anhelos y sus penas. únicamente los revolucionarios, mediante su ética de la solidaridad y fraternidad, pueden adentrarse en esa mentalidad popular ${ }^{28}$. Este principio doctrinario conlleva, empero, el peligro de que comprender abarque también las funciones de perdonar y justificar.

Gilly ha incursionado en uno de los grandes temas de las ciencias sociales latinoamericanas: los indígenas constituyen un enorme sector de la población, víctimas del odio y la violencia de los mestizos, pero asimismo humillados en los últimos siglos por ser los perdedores de una evolución histórica, la que, como es sabido, se basa ahora en la ciencia y la tecnología. Los indígenas quieren ser reconocidos en igualdad de condiciones y dignidad por los otros, los occidentalizados, pero estos últimos, apoyados anteriormente en el poder político y hoy en día en los avances científicos y técnicos de la modernidad, difícilmente lo van a hacer.

El meollo del asunto es muy complejo: Gilly y los ideólogos del indianismo no están dispuestos a ver los aspectos problemáticos en los sistemas civilizatorios que desplegaron los indígenas en el Nuevo Mundo y que perviven, por ejemplo, en las comunidades campesinas de la región andina, sistemas que no han generado la modernidad y sus evidentes ventajas en la vida cotidiana, y que además tienden a

27 Adolfo Gilly, José María Arguedas, Mario Vargas Llosa y el Papacha Oblitas, en: NUEVA SOCIEDAD (Buenos Aires), № 238, marzo-abril de 2012, pp. 60-75.

28 Ibid., pp. 70-73. 
cerrarse a un análisis crítico de sí mismos y a un cuestionamiento de su mentalidad, sus formas comunitarias de organización y su cultura política ${ }^{29}$. Y entonces, como ya se mencionó, esta corriente de pensamiento recurre a una visión simplificada del desarrollo histórico: los indígenas harían bien al iniciar un odio profundo a los representantes del colonialismo interno, a los terratenientes, al Estado manejado por los blancos y mestizos, a los extranjeros, pues ese odio sería sagrado, vivificante, una manera de fortaleza propia, de auto-afirmación ante uno mismo. La voluntad de sacrificio que nace de ese odio constituiría una especie de sacrificio histórico, que se convertiría en amor al pueblo, a los pobres y marginados ${ }^{30}$. La compensación por la dignidad perdida se revela, empero, como la consecución de actos simbólicos y gestos casi esotéricos de muy poca relevancia práctica, aunque se puede argumentar que los ajenos a esta cultura ofendida no pueden comprender el alcance y la verdadera significación de esos actos y gestos. De todas maneras: llama la atención la desproporción entre la intensidad del sentimiento colectivo de reivindicación y compensación históricas, por un lado, y la modestia de los bienes simbólicos que crean esa satisfacción, por otro. Adolfo Gilly, apoyándose en Walter Benjamin, concluye que el odio y la voluntad de sacrificio de los humillados "se nutren de la imagen de los antepasados oprimidos y no del ideal de los descendientes libres" ${ }^{31}$. Esta concepción conservadora propugna al fin y al cabo la restauración del orden social anterior a la llegada de los españoles, orden considerado como óptimo y ejemplar, lo que in praxi significaría reescribir la historia universal y negar sus resultados tangibles. Esta nostalgia por el pasado - del cual se ignoran premeditadamente los aspectos negativos - y la actitud reacia a cuestionarse uno mismo impiden contar con un orden social que dude de sí mismo, aunque esa autoconsciencia crítica sea detentada por una porción pequeña de la sociedad respectiva. Sistemas sociales relativamente simples, cerrados sobre sí mismos y opuestos a la discusión pluralista y libre acerca de alternativas, como las comunidades indígenas tradicionales y los modelos armonicistas derivados del corpus del marxismo (que creían poder integrar todas las "contradicciones" en una gran armonía utópica), han resultado ser poco flexibles y se adaptan difícilmente a entornos cambiantes. Esta ha sido probablemente una de las causas principales de la derrota de los imperios azteca e incaico frente a los conquistadores españoles: como afirma Enrique Krauze, el "aislamiento histórico" ha sido muy costoso para aquellas sociedades que no estaban abiertas al mundo y a una diversidad de opciones políticas, institucionales y militares ${ }^{32}$.

29 Cf. una amplia revisión de la literatura existente sobre la temática: Edwin Cruz Rodríguez, Movimientos indígenas y nación en Bolivia y Ecuador: la lucha por el Estado plurinacional en perspectiva histórica, en: ENCUENTROS LATINOAMERICANOS (Montevideo), vol. III, № 9, diciembre de 2009, pp. 16-54.

30 Adolfo Gilly, op. cit. (nota 27), p. 73.

31 Ibid., p. 75.- Hay que mencionar aquí que numerosos revolucionarios latinoamericanos combinan sin problema un marxismo tercamente ortodoxo con un arcaísmo ruralista, doctrinas esotéricas y elementos folklóricos de dudoso origen.

32 Enrique Krauze, Mister Prescott y Lord Thomas, en: VUELTA (México), vol. XVIII, № 216, noviembre de 1994, pp. 25-31, aquí p. 28. Cf. también: Tzvi Medin, Mito, pragmatismo e imperialismo. La conciencia social en la conquista del imperio azteca, Madrid / Frankfurt: Iberoamericana / Vervuert 2009. 
El enfoque ideológico aquí analizado, popular en el ámbito indio de América Latina, pero más expandido todavía en la esfera universitaria y académica, puede conducir a un cierto fundamentalismo. Toma cuerpo a causa de motivos comprensibles y nobles, como la defensa del propio medio, la sensación de injusticia y la exigencia de dignidad, pero tiende a mostrarse como la antítesis de la moderna civilización occidental basada en el racionalismo. Y esto posee una relevancia política de primer rango: la exigencia de dignidad y el ansia de solidaridad sin límites dejan a un lado toda reflexión sobre la proporcionalidad de los medios como algo mezquino y típicamente burgués, pues el odio y la humillación seculares son ahora la base fértil e imprescindible para la gran revolución ineludible, pero también para la creación artística y literaria ${ }^{33}$. Las compensaciones resultan ser de carácter principalmente simbólico, lo que por supuesto satisface a los intelectuales, pero no necesariamente a las masas. Esta corriente puede tomar la forma de un inofensivo movimiento patriarcalista, pero también la configuración de una sociedad anti-occidental totalitaria, que, sin embargo, quiere preservar variados logros técnicos de la modernidad occidental. Los que sustentan esta corriente son jóvenes urbanos de las capas subalternas de la sociedad y los intelectuales que no encuentran un lugar adecuado en una sociedad que se moderniza aceleradamente ${ }^{34}$.

\section{Las mentalidades premodernas y la praxis cotidiana}

Estos legados culturales han contribuido a conformar una mentalidad colectiva antipluralista y antiliberal - particularmente vigorosa en México, América Central y el área andina - que, a su vez, fomenta el surgimiento y la pervivencia de regímenes populistas con claros resabios autoritarios. Estos son sistemas sociales básicamente conservadores, pese a la doctrina del cambio radical, lo que explica en parte su fuerte arraigo en sectores poblacionales con bajo nivel educativo y de ingresos. Estos estratos sociales se orientan aun hoy por valores convencionales y rutinarios que vienen de muy atrás y que favorecen jerarquías rígidas y élites privilegiadas con respecto al ámbito organizativo, líderes carismáticos y autoritarios destinados a las jefaturas $^{35}$ y sistemas relativamente simples para la comprensión del mundo circundante (como las oposiciones binarias excluyentes: amigo / enemigo, patria / antipatria).

33 Vera Carnovale, ¿Por un mundo mejor?, en: NUEVA SOCIEDAD, № 238, marzo-abril de 2012 , pp. 88-101, especialmente p. 94.

34 Maxwell A. Cameron / Juan Pablo Luna (comps.), Democracia en la regón andina. Diversidad y desafíos, Lima: IEP 2010; Cándido Monzón Arribas / Miguel Roiz Célix / Mercedes Fernández Antón, Perfiles de una cultura política autoritaria: el Perú de Fujimori en los años noventa, en: REVISTA MEXICANA DE SOCIOLOGÍA (México), vol. 59, № 2, abril-junio de 1997, pp. 95-128.

35 El relativo apoyo colectivo en favor de Sendero Luminoso en Perú a partir de 1980, sobre todo en los sectores sociales con menor nivel educativo, tenía que ver probablemente con la estructura altamente jerárquica y piramidal de esta organización guerrillera y con su dirigencia elitaria y paternalista. Cf. Sebastian Chávez Wurm, Der Leuchtende Pfad in Peru (1970-1993). Erfolgsbedingungen eines revolutionären Projekts (Sendero Luminoso en el Perú [1970-1993]. Condiciones del éxito de un proyecto revolucionario), Colonia / Weimar: Böhlau 2011, pp. 184-193. 
La ideología indigenista e indianista aquí criticada abraza estos valores básicos de orientación. Ha sufrido, por supuesto, un proceso muy habitual de modificación teórica y enriquecimiento temático, lo que se puede observar durante el transcurso modernizante de sus respectivas sociedades, sobre todo en la segunda mitad del siglo XX. Esto ha favorecido igualmente una sutil utilización de esta ideología con fines políticos. En la actualidad sus antiguos contenidos éticos (relativos, por ejemplo, a la solidaridad inmediata, la homogeneidad de la comunidad y la fraternidad entre los integrantes de la misma) mantienen una relevancia sólo verbal, mientras que sus normativas autoritarias han experimentado un considerable renacimiento y ahora son empleadas cotidianamente para "acercar" a las masas hacia metas que definen unilateralmente las dirigencias de los partidos populistas. Estos aspectos poco promisorios no han concitado el interés de muchos especialistas extranjeros en torno a los regímenes populistas, que más bien se han destacado en la apología académica de estos últimos ${ }^{36}$.

En el marco de este ensayo es de justicia mencionar que los sistemas populistas también contienen diversos elementos positivos, que pueden ser descritos sucintamente con las palabras de Pablo Stefanoni como la búsqueda de un equilibrio entre el capital financiero y el productivo, más Estado y más inversión pública, mayores derechos para los trabajadores ("Ahora hay patria para todos"), el objetivo de generar un nuevo pacto social y el intento de superar el llamado colonialismo interno ${ }^{37}$. Sin embargo: a lo ancho del Tercer Mundo varios sistemas sociales han conseguido logros similares, sin necesidad de usar recetas populistas, como lo muestran en tres continentes los ejemplos de Costa Rica, Corea del Sur y Botswana.

No hay duda de la inmensa importancia de temas como la exclusión social persistente, los fenómenos de desigualdad paralelos a la consolidación de la democracia $^{38}$ y las consecuencias prácticas del creciente reconocimiento de las culturas aborígenes desde el Estado y la sociedad, pero al mismo tiempo hay que investigar el peso de la herencia cultural de los grandes sistemas civilizatorios precolombinos en su mixtura con la tradición iberocatólica, y especialmente en lo referente a sus secuelas para la cultura política contemporánea y la producción de

36 Cf. por ejemplo el volumen: Leo Gabriel / Herbert Berger (comps.), op. cit. (nota 6); Hans-Jürgen Burchardt, Zeitenwende - Politik nach dem Neoliberalismus (Cambio de épocas - política después del neoliberalismo), Stuttgart: Schmetterling 2004; Hans-Jürgen Burchardt, Tiempos de cambio - repensar América Latina, San Salvador: Fundación Böll 2007; Adrian J. Pearce (comp.), Evo Morales and the Movimiento al Socialismo in Bolivia: The First Term in Context, 2006-2010, Londres: University of London / Institute for the Study of the Americas 2011; Robert Lessmann, Das neue Bolivien. Evo Morales und seine demokratische Revolution (La nueva Bolivia. Evo Morales y su revolución democrática), Zurich: Rotpunktverlag 2010.

37 Pablo Stefanoni, Posneoliberalismo cuesta arriba. Los modelos de Venezuela, Bolivia y Ecuador en debate, en: NUEVA SOCIEDAD, No 239, mayo-junio de 2012, pp. 51-64, aquí p. 52.

38 Hans-Jürgen Burchardt, ¿Por qué América Latina es tan desigual? Tentativas de explicación desde una perspectiva inusual, en: NUEVA SOCIEDAD, No 239, mayo-junio de 2012, pp. 137-150; Hans-Jürgen Burchardt, Democracia y desigualdad, en: NUEVA SOCIEDAD, № 215, mayo / junio de 2008, pp. 79-84. 
ideologías y elementos propagandísticos de gran eficacia y resonancia. Los autores partidarios de los regímenes populistas latinoamericanos se dedican a una gran cuestión ética e histórica, que es la explicitación teórica del rechazo del neoliberalismo en particular y del capitalismo globalizador en general ${ }^{39}$, pero descuidan los efectos y resultados de la carencia de instituciones y procedimientos democrático-liberales en dos esferas: la vida de los partidos políticos, principalmente del populista en funciones gubernamentales, y la marcha cotidiana de la administración pública.

Como afirma un estudio sobre el gobierno populista boliviano (desde enero de 2006), lo que también distingue a este régimen en la prosaica existencia cotidiana es el secretismo, la discrecionalidad y la vasta corrupción de la administración pública ${ }^{40}$. El partido gubernamental (Movimiento al Socialismo, MAS), que tiene su principal base electoral en las etnias indígenas del país, reproduce viejas usanzas autoritarias, paternalistas y prebendalistas, transladando, por ejemplo, el clásico conflicto por puestos y espacios de poder desde una esfera abierta y pública - la competencia entre partidos y grupos políticos - hasta un ámbito reservado y cerrado: el interior del partido gubernamental, que no ha conocido ningún rasgo de democracia interna ${ }^{41}$. Hasta hoy el MAS no se ha dotado de una ideología propia; la jefatura no permite un debate intelectual-ideológico en su seno. Un estudioso vinculado a las izquierdas atribuye al MAS una total incomprensión de la necesidad de construir un espacio público y de lo que significa democracia interna ${ }^{42}$. En la praxis diaria los segmentos elitarios compiten dentro del MAS por la hegemonía política y el apoyo del aparato estatal, pero se trata de una pugna recatada y cautelosa, propia de las tradiciones y los hábitos de las antiguas clases privilegiadas, pugna que ahora está en manos de los sectores ligados a la economía informal ( $\mathrm{y}$ a la delictiva), que por ello no pueden estar interesados en una actuación transparente y basada en criterios racionales de largo plazo. El carácter conservador del régimen aflora en el tradicional desinterés por los derechos de terceros y en la preeeminencia desmedida que se atribuye a la astucia y la picardía. La política aparece entonces como la actividad primordial de intereses sectoriales en lucha sorda, sin que exista una genuina preocupación por el bien común, salvo en la retórica destinada a los ingenuos. El partido populista en el poder, prosiguiendo las convenciones más enraizadas de la sociedad boliviana y mediante la expansión del Estado hacia el terreno económico, se ha convertido en el

39 Cf. por ejemplo: Gilberto López y Rivas, op. cit. (nota 6), p. 71; Herbert Berger, Chile: Die Abwahl der Mitte - Neoliberalismus versus Kosmovision (Chile: rechazo al centro - neoliberalismo versus cosmovisión), en: Leo Gabriel / Herbert Berger (comps.), op. cit. (nota 6), pp. 17-52; Pablo Ospina / Olaf Kaltmeier (comps.), Los Andes en movimiento. Identidad y poder en el nuevo paisaje político, Quito: Corporación Editora Nacional 2009.

40 Henry Pinto Dávalos, Arcana imperii: Estado, secreto, transparencia y poder, en: ESTUDIOS POLíTICOS (Cochabamba), vol. III, № 3, febrero de 2012, pp. 71-78, especialmente p. 73. Muy similar: Pablo Stefanoni, Bolivien unter Evo Morales: von der Mobilisierungslogik zur Entwicklungsdisziplin? (Bolivia bajo Evo Morales: de la lógica de la movilización a la disciplina del desarrollo?), en: INTERNATIONALE POLITIK UND GESELLSCHAFT, vol. 2010, № 3, pp. 63-76, aquí p. 69.

41 Fernando Molina, El MNR de los 50 y el MAS: partidos de Estado, en: PULSO (La Paz) del 6 de diciembre de 2009, vol. 10, No 531, p. 8.

42 Pablo Stefanoni, op. cit. (nota 40), p. 74. 
gran distribuidor de fondos, puestos y prestigio. El control de los canales de acceso al aparato estatal le ha brindado "su enorme capacidad de cooptación y deglución"43 de personalidades, partidos, grupos y, obviamente, ideales. Este orden, caracterizado por el sigilo, la arbitrariedad y el favoritismo, no puede promover el Estado de derecho y la previsibilidad de las acciones gubernamentales ${ }^{44}$.

En los otros modelos populistas de América Latina la constelación es muy similar. Como afirmó Peter Waldmann en un detallado análisis del caso argentino ${ }^{45}$, el aparato estatal se convierte en un objeto de explotación y aprovechamiento particular: la ideología de lo social-colectivo funciona como una pantalla notablemente eficaz - que encubre la utilización egoísta-individualista de los recursos públicos. A largo plazo la ideología y la praxis populistas dan lugar a niveles débiles de institucionalidad, a un estatismo ineficiente y derrochador, a la incapacidad del Estado de hacer respetar sus normas legales y, en general, a un sistema social muy convencional que vive de la exportación de recursos naturales y que se caracteriza por la lucha continua en torno a la repartición de las rentas fiscales ${ }^{46}$. El extractivismo rutinario se complementa con la visión tradicional y casi religiosa del maná: un medio ideal de subsistencia que cae del cielo sin esfuerzo propio y de manera igualitaria sobre todos, como la gente sencilla se imagina, por ejemplo, las secuelas de la renta petrolera.

Durante largas décadas estos factores han moldeado en América Latina una variante de la mentalidad colectiva que exhibe rasgos premodernos, pues se trata de una concepción muy difundida que no se pone a sí misma en cuestionamiento, ni reconoce la relevancia social del espíritu crítico, ni tampoco aprecia positivamente las comparaciones con el mundo exterior. Lo que podríamos llamar la esfera prepolítica está condicionada por esos valores de orientación que promueven el advenimiento de regímenes populistas, a menudo de manera indirecta, pero muy efectiva en la praxis. En Bolivia, una sociedad relativamente cerrada sobre sí misma, el ámbito prepolítico y sus tradiciones convencional-rutinarias son en parte responsables por la considerable popularidad actual de un presidente carismático y autoritario, lo que lleva a muchos analistas a concluir que este régimen sería la culminación de los anhelos profundos de la población ${ }^{47}$.

En toda América Latina la herencia cultural es propicia al caudillismo: en tiempos de crisis el líder providencial aparece como la solución adecuada, por ser fácilmente

43 Fernando Molina, op. cit. (nota 41), p. 8.

44 Diego Ayo, Volverán las oscuras, muy oscuras golondrinas, en: PÁGINA SIETE del 29 de enero de 2012, suplemento IDEAS (vol. II, No 86), p. 5.

45 Peter Waldmann, Argentinien. Schwellenland auf Dauer (Argentina. El país en despegue permanente), Hamburgo: Murmann 2010, p. 183.

46 Como lo reconoce un analista liminarmente favorable a los regímenes populistas: Pablo Stefanoni, op. cit. (nota 37), pp. 52-53.

47 Cf. un apología de este proceso que hace abstracción de la mentalidad colectiva y de los aspectos institucionales: Robert Lessmann, Bolivien: der steinige Weg zum plurinationalen Staat (Bolivia: el camino pedregoso hacia el Estado plurinacional), en: Leo Gabriel / Herbert Berger (comps.), op. cit. (nota 6), pp. 145-163. 
comprensible para los sectores con niveles educativos menores. Como asevera Fernando Molina refiriéndose al caso boliviano, el caudillo está por encima de la laboriosa construcción de consensos, del debate pluralista y de las minucias de la vida institucional. La sociedad convencional confía más en el líder providencial que en el trabajo continuado y complejo de las instituciones ${ }^{48}$.

Lo problemático reside en el hecho de que el caudillo, el iluminado, el señalado por la historia, no conoce limitaciones a su actuación y perpetúa el legado rutinario de arbitrariedad e imprevisibilidad en la esfera pública. Aunque la retórica puede adquirir aspectos progresistas y un tinte socialista de acuerdo a las corrientes de la época, en la realidad cotidiana los regímenes populistas retornan a lo más habitual de la tradición latinoamericana, como lo demuestran continuamente los regímenes de Bolivia, Ecuador, Nicaragua y Venezuela. Desatienden el Estado de derecho, dificultan el control racional y público de las actuaciones gubernamentales y entorpecen el debate abierto y pluralista de opciones políticas, y por ello patrocinan el surgimiento de una élite gobernante convencional y poco razonable: el reino de los más fuertes y más astutos. La consecuencia ineludible es la constitución de un estrato elitario que, en el fondo, preserva el extendido ámbito de la inmovilidad, la intransparencia y la arbitrariedad. Bajo el manto de la reforma radical se reproducen así las rutinas más enraizadas y difundidas del orden prerrevolucionario. En suma: en el ejercicio del poder los dirigentes populistas, que comienzan luchando por los derechos de los excluidos de la historia latinoamericana, se transforman en los miembros de una nueva élite de privilegiados, que a menudo exhiben rasgos despóticos y casi siempre terminan muy alejados del pueblo llano, tanto en sentido económico como cultural $^{49}$. Mediante la utilización astuta y egoísta de los recursos fiscales y de la protección que brinda a los suyos el gobierno populista, este estrato de militantes privilegiados mantiene viva la tradición latinoamericana de clases altas que viven del aparato estatal, poseen una influencia decisiva sobre las políticas públicas y no tienen ninguna responsabilidad ante el conjunto de la sociedad.

Todo esto no es, evidentemente, una contribución a un nuevo modo de vida basado en la igualdad y la fraternidad de los ciudadanos, ni tampoco un renacimiento de formas arcaicas, pero solidarias que habrían existido antes de la conquista española, que se habrían conservado en algunas comunidades campesino-indígenas de tierras altas y que ahora la doctrina oficial del indigenismo convertiría en pautas normativas de la vida diaria. Los grupos de privilegiados en cuanto nuevas clases dominantes tampoco significan una genuina modernización de la sociedad respectiva mediante la introducción de un individualismo emprendedor e innovador como se desarrolló en Europa Occidental desde el Renacimiento. La constelación es algo diferente en las naciones de América Latina que han alcanzado un grado más avanzado de modernización cultural, como Argentina. En un estudio sobre este país Peter

48 Fernando Molina, La institución de la personalidad, en: PULSO del 19 de diciembre de 2009, vol. 10, № 532, p. 5; Fernando Molina, Sin orden no hay justicia, en: PÁGINA SIETE del 11 de mayo de 2012, p. 17.

49 Sergio Ramírez, Los monstruos de la razón, en: NUEVA SOCIEDAD, № 238, marzo-abril de 2012, pp. 4-15, aquí p. 6. 
Waldmann ha detectado un "individualismo excesivo", al que le sería propio un fuerte anhelo de autonomía, pero también un componente altamente antisocial y antiinstitucional $^{50}$. Esta inclinación a velar exclusivamente por los intereses propios se conjugaría, según Waldmann, con la carencia de un marco normativo generalmente aceptado, lo que impediría el despliegue del Estado de derecho y la difusión del respeto auténtico por los derechos de terceros y por las leyes y regulaciones vigentes $^{51}$.

No hay duda, por otra parte, de que esta variante de un individualismo que "rompe reglas" - de acuerdo a Waldmann - dificulta asimismo la constitución de normas que crean confianza entre los actores sociales; se trata, además, de un comportamiento repetitivo que no está dispuesto a reconocer abierta y sinceramente el desempeño y los valores de los otros ciudadanos. Es probable que el estancamiento socioeconómico casi permanente de Argentina, después de un brillante comienzo, y el largo predominio del peronismo tengan que ver directamente con ese individualismo excesivo. La versión "suave" del populismo en Argentina, el peronismo, es probablemente una de las causas centrales de una evolución que ha obstaculizado que este país tenga hoy un desarrollo comparable al de Canadá o Australia.

Comentando el enfoque de Peter Waldmann, habría que decir que en la mayor parte de América Latina no se ha dado un individualismo moderno y creativo. Mejor dicho: no se ha difundido un individualismo en sentido estricto, sino una actitud elemental de defensa permanente contra el prójimo, bajo un barniz de modernización incipiente: una normativa básica de supervivencia en un medio hostil, que ya no es el orden arcaico de una sociedad rural y que todavía no ha producido las reglas sociales de un medio urbano comparable al ámbito occidental. Esta es probablemente la situación actual bajo los gobiernos populistas en Bolivia, Ecuador, Nicaragua y Venezuela, donde se puede registrar un retroceso civilizatorio en lo referente al funcionamiento de la administración pública, a las interacciones diarias de los grupos dominantes entre sí y a la configuración de la esfera política en general. No hay duda de que los regímenes populistas llegaron al poder mediante el voto electoral y se consolidaron por mucho tiempo porque han sido favorecidos por la prevalencia de estas pautas generales de comportamiento. Sobre todo en el área andina, América Central y México nos encontramos con sistemas sociales que se están modernizando aceleradamente en sus regiones urbanas, pero donde aun existen sectores poblacionales en los que se puede constatar una combinación de colectivismo vigoroso (que no reconoce al individuo como algo único e irreemplazable) con una utilización entusiasta, pero acrítica, de instrumentos técnicos modernos. Todo esto no puede ser calificado como individualismo en sentido estricto, sino como una pauta generalizada de comportamiento que resulta ser adecuada para la defensa elemental de uno mismo (perjudicando al prójimo como primera medida profiláctica), pero ineficaz para producir innovaciones y emprendimientos valiosos para la evolución del país respectivo a largo plazo.

\footnotetext{
50 Peter Waldmann, op. cit. (nota 45), p. 192.

51 Ibid., p. 193, 196.
} 
Todos los sistemas sociales han exhibido una distancia evidente entre la retórica oficial y la praxis cotidiana, entre los postulados programáticos y la prosaica realidad de cada día. En el caso del populismo latinoamericano esta distancia está agravada por una ideología del cambio radical, exornada con los elementos contemporáneos del nacionalismo y el socialismo, la cual encubre exitosamente la continuidad de prácticas rutinarias y convencionales de una tradición básicamente irracional en el campo socio-político. Tenemos entonces una retórica que identifica con vehemencia a los enemigos y a los culpables de todos los males (el imperialismo, las oligarquías sociales, la conquista ibérica, el neoliberalismo). Pero no se preocupa adecuadamente de las pautas recurrentes de comportamiento y de las imágenes irreales del futuro. La retórica populista y lo que podríamos llamar la producción teórica asociada a esta ideología no generan una posición crítica con respecto a sus propias carencias, sus errores manifiestos y el ámbito de sus privilegiados. La configuración práctico-cotidiana del populismo no ingresa en la mira de sus preocupaciones teóricas. En Bolivia, Ecuador, Nicaragua y Venezuela se da hoy una propaganda gubernamental altisonante, que apela directamente a los sentimientos $y$, ante todo, a los prejuicios de las masas ciudadanas, pero estas corrientes políticas rara vez se esfuerzan por educar racionalmente a sus adherentes y por mostrarles las deficiencias concretas que son habituales en la vida social.

En los países mencionados falta una pedagogía crítica con respecto a la propia realidad e historia. Es cierto que las masas, en todas las sociedades, no quieren ser desilusionadas mediante el conocimiento y no pierden fácilmente su ímpetu entusiasta por caudillos y movimientos que les ofrecen una vida mejor en el corto plazo y sin gran esfuerzo individual, pero los gobiernos populistas de la actualidad se consagran con una energía admirable a seducir a las masas mediante las técnicas más refinadas de la moderna comunicación social.

En Bolivia, Ecuador, Nicaragua y Venezuela la propaganda gubernamental y la ideología de los gobiernos populistas están consagradas a las grandes metas históricas, por una parte, y al combate de los muchos enemigos, por otra. Se lucha por programas irrealistas y altisonantes y se aceptan estoicamente las estrecheces del presente porque se supone que el mañana - radiante y revolucionario solucionará todos los problemas imaginables. Esta inclinación a generalidades eufónicas y a descuidar el debate racional de lo concreto proviene de la herencia colonial ibérica y la republicana de los últimos siglos; el populismo contemporáneo la ha revigorizado con notable virtuosismo. A estas prácticas corresponde también la instrumentalización del pensamiento ajeno para los fines prosaicos del momento ${ }^{52}$. Asuntos concretos como la inseguridad ciudadana, el mal desempeño de la policía y

52 Sobre la manipulación del pensamiento de Simón Bolívar por el régimen chavista cf. la investigación exhaustiva de María Teresa Moser, Das Gedankengut von Simón Bolívar und seine Instrumentalisierung durch Hugo Chávez in Venezuela (El pensamiento de Simón Bolívar y su instrumentalización por Hugo Chávez en Venezuela), Frankfurt: Peter Lang 2011.- Chávez se integra en una larga lista de gobernantes venezolanos que desde el siglo XIX han utilizado la figura y la obra de Bolívar para los fines más diversos. 
de otras fuerzas del orden público (juzgados, fiscalías) y la progresiva desinstitucionalización del aparato estatal no constituyen temas importantes o interesantes para estos gobiernos. No es superfluo señalar que estas cuestiones representan materias muy secundarias y hasta insustanciales para una buena parte de los pensadores de tendencias indianistas e indigenistas, socialistas y revolucionarias, nacionalistas y nativistas.

En toda América Latina, y de manera creciente en regímenes populistas, la burocracia estatal y la administración de justicia hacen perder tiempo - el bien más preciado, por ser el único irrecuperable - a los ciudadanos (mejor dicho: a los súbditos) con trámites enmarañados y procedimientos innecesarios, todos mal diseñados. Aquí se percibe claramente la falta de una pedagogía crítica: por un lado, los gobiernos populistas no hacen nada por mejorar esta situación - en estos sistemas se percibe más bien una propensión a complicar toda la esfera burocrática -, y no existe, por otro, una consciencia pública crítica en torno a esta temática. Todo roce con el Poder Judicial y el Ministerio Público conlleva una pérdida de tiempo, dinero y dignidad para los afectados, pero no existe un movimiento de los damnificados para paliar esta situación. Son precisamente los pobres de los pobres las víctimas mayoritarias de esta constelación y, al mismo tiempo, los más reacios a protestar claramente contra estos fenómenos. La gente humilde supone que se trata de procesos naturales en sentido estricto, como terremotos o tempestades, ante los cuales la única actitud razonable es la pasividad y la paciencia.

En general los dirigentes de los partidos populistas, los instigadores de tendencias indigenistas e indianistas y, obviamente, los intelectuales progresistas jamás se molestan en considerar en serio estas carencias de la vida social. Hay que señalar en descargo de ellos que la preocupación por estos asuntos concretos no rendiría ventajas políticas inmediatas ni prestigio social utilizable. Se supone que estos "detalles" desagradables de la vida cotidiana - los epifenómenos de la superestructura, según los marxistas -, serán barridos automáticamente por las grandes medidas revolucionarias.

\section{Los sistemas populistas en retrospectiva}

El paradigma nacionalista-populista de desarrollo - recubierto a menudo con un barniz de socialismo radical - ha gozado de una popularidad masiva y de una notable reputación intelectual durante una buena parte del siglo XX y comienzos del XXI. El peronismo argentino es sólo el ejemplo más claro y más estudiado de ello ${ }^{53}$. Dos factores concatenados entre sí expandieron esta concepción en extensas porciones de América Latina: la idea de que el orden tradicional, rural y pre-industrial constituiría un sistema político injusto, carente de dinamismo e históricamente superado, y la ilusión de que el progreso técnico-económico traería consigo automáticamente la

53 Cf. Peter Waldmann, El peronismo 1943-1955, Buenos Aires: Universidad Nacional de Tres de Febrero (EDUNTREF) 2009. 
justicia social. En todos los modelos latinoamericanos del cambio radical este proceso de modernización técnica y aceleración económica estuvo concebido como algo dirigido y dosificado desde el Estado, sin consulta de los estratos subalternos ${ }^{54}$. Esta adaptación relativamente autoritaria del progreso técnico no debía incluir la atmósfera cultural y el liberalismo político que han caracterizado la modernidad en el ámbito occidental. Al mismo tiempo, el orden "revolucionario" debía recuperar las tradiciones, los valores y las prácticas populistas de las masas que fueron habituales desde la independencia ${ }^{55}$.

Para comprender hoy en día la energía que irradiaban sistemas populistasreformistas, como el peronismo en Argentina (1943-1955) y la llamada Revolución Nacional en Bolivia (1952-1964) ${ }^{56}$, su capacidad de movilización popular y su lugar relativamente positivo en las ciencias sociales e históricas, hay que imaginarse la fascinación que irradiaba esta ideología sobre los más variados estratos sociales y grupos intelectuales. El término fascinación alude al hecho de que numerosos factores prerracionales se encontraban en los cimientos de aquel impulso cultural y político. Hay que reconstruir esa especie de consenso general para entender la fuerza avasalladora que han tenido el populismo en el siglo XX y sus variantes contemporáneas en el XXI, ese sentido común elaborado exitosamente por sus propagandistas, que perdura hasta nuestros días contaminando el imaginario colectivo del país respectivo mediante un ímpetu prelógico.

Ese consenso general puede ser descrito sumariamente como el intento, bastante exitoso en los hechos concretos, de combinar una amplia movilización de la sociedad y una incipiente modernización técnico-económica con el rescate de prácticas, rutinas y convenciones del orden tradicional. Este desarrollo, cuyos factores positivos están fuera de duda y que ya han sido nombrados en este texto, contiene también tres elementos negativos que a la postre caracterizan el populismo latinoamericano: (1) La consolidación de la cultura política del autoritarismo, (2) la formación de élites muy privilegiadas que pasan a constituir las nuevas clases altas y (3) la desinstitucionalización de la vida público-política, con su secuela inevitable, la corrupción en gran escala.

(1) La principal herencia a largo plazo de los regímenes populistas ha sido la preservación y exacerbación de normativas premodernas y prerracionales en el

54 Una primera formulación de esta problemática: Gino Germani, Política y sociedad en una época de transición. De la sociedad tradicional a la sociedad de masas, Buenos Aires: Paidós 1965.- Para una versión diferente cf. Nora Rabotnikof / Julio Aibar, El lugar de lo público en lo nacional-popular. ¿Una nueva experimentación democrática?, en: NUEVA SOCIEDAD, № 240, julio-agosto de 2012, pp. 54-67.

55 Cf. Guy Hermet / Soledad Loaeza / Jean-François Prud'homme (comps.), Del populismo de los antiguos al populismo de los modernos, México: El Colegio de México 2001; Ludolfo Paramio, Giro a la izquierda y regreso del populismo, en: NUEVA SOCIEDAD, No 205, septiembre-octubre de 2006, pp. 62-74.

56 Cf. las obras que no han perdido vigencia: Herbert S. Klein, Orígenes de la Revolución Nacional boliviana. La crisis de la generación del Chaco, La Paz: Juventud 1987; James M. Malloy, Bolivia: The Uncompleted Revolution, Pittsburgh: Pittsburgh U. P. 1970. 
campo socio-cultural. Los partidos populistas han sido y son organizaciones donde predominan prácticas muy arraigadas y difíciles de modificar, cuyo carácter es básicamente conservador-tradicional, como el caudillismo y el prebendalismo, la propensión a la maniobra oscura y a la intriga permanente. Estas rutinas y convenciones no están codificadas por escrito, pero reglamentan la vida interna y cotidiana de los partidos, establecen las diferencias reales entre dirigencia y masa, determinan los canales fácticos de comunicación entre los diversos grupos, atribuyen autoridad decisiva a los jefes con virtudes carismáticas y delimitan la verdadera significación de programas e ideales. Estos hábitos perviven pese a todos los contactos con el mundo exterior y al uso cotidiano de los últimos inventos de la tecnología.

A través de su accionar cotidiano se puede percibir que el éxito de los partidos populistas está vinculado con un renacimiento de la cultura política tradicional. En países como Bolivia, Ecuador, Nicaragua y Venezuela los intentos históricos de establecer una genuina cultura liberal-democrática no tuvieron éxito porque esta última nunca había echado raíces duraderas en estas sociedades y era considerada como extraña por la mayoría de la población. Los movimientos populistas, en el fondo, representan y prorrogan la tradición autoritaria, centralista y colectivista de la nación profunda, tradición muy arraigada en el ámbito rural, la población indígena y los grupos sociales que habían permanecido secularmente aislados del mundo exterior. Todo advenimiento de regímenes populistas ha sido considerado por una parte de la opinión pública como un sano retorno a la propia herencia nacional, a los saberes populares de cómo hacer política y a los modelos ancestrales de reclutamiento de élites y también como un necesario rechazo a los sistemas foráneos y cosmopolitas del "imperialismo capitalista".

(2) En la dura realidad cotidiana los modelos populistas se han distinguido por la creación de élites sociales muy reducidas, privilegiadas y excluyentes, similares a las clases altas tradicionales que estos sistemas dicen combatir. Las nuevas élites reproducen las características negativas de las antiguas oligarquías: la arrogancia infundada, el desprecio por la cultura y la ciencia, la incapacidad de generar visiones de largo plazo y la explotación sin escrúpulos de los estratos subalternos del país.

Desde un comienzo las posiciones de dirigencia fueron ocupadas principalmente por personas hábiles en cuestiones de corto plazo y sin muchas consideraciones éticas. Aquí se nota, otra vez, el rasgo básicamente conservador de los experimentos populistas. Estos operadores, por definición, son expertos en relaciones públicas, técnicos sin adscripciones ideológicas profundas; trabajan en realidad al servicio del mejor postor. Las destrezas específicas de los operadores residen en campos delimitados: los juegos estratégicos, las negociaciones, la obtención y consolidación de espacios de poder, las maniobras y las intrigas (que pueden ser de una gran complejidad), la elaboración de algunas ideas a la moda - muy simples, por supuesto - para las campañas electorales y tejer una red de contactos con las organizaciones internacionales, los empresarios y los medios de comunicación. Los militantes más exitosos de los partidos populistas son probablemente aquellos que tienen como 
metas normativas la consecución de dinero y poder, y para quienes los objetivos ideológicos tienen un valor meramente instrumental. El saber manipular símbolos es algo muy útil para consolidar y mejorar la propia posición dentro del partido y el gobierno, pero el cumplimiento real de metas programáticas no ocasiona preocupación alguna dentro de estas agrupaciones y menos dentro de la nueva clase privilegiada. Los expertos de los juegos estratégicos y de la astucia irrestricta olvidan empero una dimensión fundamental de la política. Hay una diferencia importante entre el saber intelectual y las picardías de la política cotidiana: el operador puede moverse muy bien en los entresijos del poder mediante una estrategia instrumental, pero no comprende el conjunto social ni puede percibir los fenómenos que van allende lo muy conocido, que son en general los procesos evolutivos de largo aliento. Los operadores no pueden brindar lo que esperan dilatados sectores sociales: el componente ético, la vocación de servicio a la comunidad, las visiones de futuro y la constelación sostenida por la confianza y la dignidad.

(3) En función gubernamental los movimientos populistas han dedicado una parte de sus energías a debilitar el Estado de derecho, a tolerar la existencia de códigos paralelos en la esfera pública, a fomentar prácticas corruptas dilatadas y a desmantelar los organismos estatales de índole moderna, como las cortes constitucionales. La instrumentalización del aparato judicial en favor de planes y decisiones políticas del Poder Ejecutivo es uno de los rasgos más conocidos de los actuales gobiernos de Bolivia, Ecuador ${ }^{57}$, Nicaragua ${ }^{58}$ y Venezuela. Los agentes del orden público - los tribunales, los jueces y fiscales, las fuerzas armadas y la policía experimentan un menoscabo de su autonomía y una declinación de su formación profesional. Otro elemento concomitante es un significativo aumento de la inseguridad jurídica. La utilización astuta de los códigos paralelos constituye una de las claves explicativas de la fortaleza de los movimientos populistas.

Como aseveró Manfred Mols, a muchos estudios referidos a América Latina les falta profundidad histórico-cultural, sensibilidad contextual y criterios adecuados de valoración $^{59}$. O sea: algo de hermenéutica crítica. Por ello este texto intenta ser un ensayo interpretativo, que no renuncia a juicios valorativos. Como conclusión se puede afirmar que el populismo y algunas formas de socialismo y nacionalismo representan un modelo de lucha contra la ambigüedad liminar del mundo moderno y sus expresiones culturales y políticas, como el individualismo generalizado, el

57 Cf. Carlos de la Torre, Populist Seduction in Latin America. The Ecuadorian Experience, Columbus: Ohio U. P. 2010.- Para una versión diferente cf. Sofía Cordero Ponce, Estados plurinacionales en Bolivia y Ecuador. Nuevas ciudadanías, ¿más democracia?, en: NUEVA SOCIEDAD, N 240, julio-agosto de 2012, pp. 134-148.

58 Cf. Andrés Pérez-Baltodano, El regreso del sandinismo al poder y la cristalización del "Estadomara", en: NUEVA SOCIEDAD, No 219, enero-febrero de 2009, pp. 4-13; Salvador Martí i Puig, Nicaragua y el FSLN (1979-2009). ¿Qué queda de la revolución?, Barcelona: Bellaterra 2009.- Para una versión diferente cf. Armando Chaguaceda, Régimen político y estado de la democracia en Nicaragua. Procesos en desarrollo y conflictos recientes, en: NUEVA SOCIEDAD, № 240 , julio-agosto de 2012, pp. 163-174.

59 Manfred Mols, Der Staat in der "Dritten Welt", (El Estado en el "Tercer Mundo"), en: KASAUSLANDSINFORMATIONEN, vol. 27, № 11, noviembre de 2011, pp. 124-157, aquí p. 125. 
pluralismo ideológico y la concurrencia perenne de partidos. Estas tendencias aprecian e imitan, sin embargo, la modernidad técnico-económica, pero no están dispuestas a aceptar la atmósfera racional, crítica y liberal que fue el fundamento del mundo actual basado en la ciencia y la tecnología. Son corrientes que miran hacia atrás en sentido cultural: celebran las jerarquías sociales, el colectivismo uniformador, los gobiernos omniscientes, la fidelidad hacia las propias tradiciones y la unanimidad de pareceres. Por ello y por contraste nos queda un criterio para juzgar a un régimen político: la capacidad para mantener una apertura hacia nuevos y diversos desarrollos. 